\title{
Effect of an isolated mild to moderate ischemic brain injury in the gastric emptying of liquids in rats ${ }^{1}$
}

\author{
Efeito de lesão cerebral hipóxico-isquêmica isolada no esvaziamento gástrico de uma solução \\ salina em ratos
}

\author{
Ana Paula Campos Melro', Edgard Ferro Collares ${ }^{I I}$, Joaquim Murray Bustorff Silva ${ }^{\text {III }}$ \\ ${ }^{\mathrm{I}} \mathrm{MD}$, Fellow Master degree, Department of Surgery, State University of Campinas (UNICAMP), Sao Paulo, Brazil. \\ II PhD, Full Professor, Division of Pediatric Gastroenterology, Medical School, UNICAMP, Sao Paulo, Brazil. \\ ${ }^{\text {III }} \mathrm{PhD}$, Full Professor, Division of Pediatric Surgery, Department of Surgery, Medical School, UNICAMP, Sao Paulo, Brazil.
}

\begin{abstract}
Purpose: To evaluate the effect of hypoxic-ischemic brain injury over the gastric emptying of liquids in rats. Methods: Fifty-two Wistar rats aged six weeks and weighing between $100 \mathrm{~g}$ and $150 \mathrm{~g}$ were divided in three groups. A Control group (C), a Sham group (S) undergoing sham procedure, and a Hypoxic-ischemic group (HI) consisting of 18 animals undergoing surgical ligature of the left carotid artery and exposure to hypoxic environment for three hours. Half of the animals were studied in the third day post-HI procedure (Early) and nine in the $14^{\text {th }}$ day post-HI procedure (Late). Gastric emptying was evaluated by an infusion technique using fenolsulftalein as a marker. Results: After the HI procedure, all animals displayed left eyelid ptosis, and six animals showed minor sideway gait. Histological examination confirmed de brain injury in all animals from the HI group. There was no statistical significant difference among the mean gastric retention values of the three groups neither in the Early nor in the Late evaluation. Conclusion: Isolated HI brain injury was not associated with delayed gastric emptying.
\end{abstract}

Key words: Gastric Emptying. Gastroesophageal Reflux. Saline Solution, Hypertonic. Rats.

\section{RESUMO}

Objetivo: Avaliar o efeito de lesão cerebral hipoxico-isquêmica sobre esvaziamento gástrico (EG) de líquidos em ratos. Métodos: Cinqüenta e dois ratos Wistar com seis semanas de idade e pesando entre $100 \mathrm{~g}$ e $150 \mathrm{~g}$ foram divididos em três grupos. Um grupo Controle (C), um grupo Sham (S) de 18 animais submetidos a manipulação da artéria carótida esquerda sem ligadura e um grupo Hipoxico-isquêmico (HI) que consistiu de 18 animais submetidos a ligadura cirúrgica da artéria carótida esquerda e exposição a ambiente hipóxico por três horas. Metade dos animais foi estudada no terceiro dia pós-procedimento (Precoce) e a outra metade no $14^{\circ}$ dia pós-procedimento (Tardio). O EG de uma solução salina foi avaliado por uma técnica de infusão usando a fenolsulftaleína como um marcador. Resultados: Após o procedimento de HI, todos os animais apresentaram ptose palpebral à esquerda e seis animais mostraram leve desvio da marcha. O exame histológico do cérebro confirmou lesão cerebral em todos os animais do grupo HI. Não foi observada diferença estatística significativa entre os valores médios da retenção gástrica dos três grupos nem nas observações Precoces nem nas Tardias. Conclusão: A lesão cerebral difusa isolada provocada por um episódio HI não esta associada com retarde de esvaziamento gástrico de uma refeição líquida não calórica.

Descritores: Esvaziamento Gástrico. Refluxo Gastroesofágico. Solução Salina Hipertônica. Ratos.

${ }^{1}$ Research performed at the Center for Experimental Medicine and Surgery, State University of Campinas (UNICAMP), Sao Paulo, Brazil.

\section{Introduction}

Although a great number of clinical studies have demonstrated an increased incidence of severe gastroesophageal reflux disease (GERD) among neurological impaired (NI) children ${ }^{1-3}$, the reasons for this association are still poorly understood ${ }^{4-6}$. Reports of an increased risk of failure of both clinical and surgical treatment of GERD among NI children suggest that different pathophysiological mechanisms may be involved ${ }^{7-10}$. Among others, the hypothesis of a diffuse gastrointestinal motility disorder being responsible for the reflux has recently gained acceptance ${ }^{4,5}$. However, because of the ethical and technical problems associated with the clinical evaluation of those children, there is a lack of well controlled studies addressing this issue. It is believed that understanding the changes in the gastrointestinal physiology present in NI children, may help to improve the quality of their treatment.

The purpose of this study is to evaluate the effect of a diffuse brain injury in the gastric emptying of a liquid meal using a well established animal model of hypoxic-ischemic (HI) neurological lesion ${ }^{11}$. 


\section{Methods}

Fifty-two Wistar male rats aged six weeks and weighing between $100 \mathrm{~g}$ and $150 \mathrm{~g}$ were used in the experiment. The study was approved by the Bioethical Committee for Animal Experimentation of the Institute of Biology of the State University of Campinas. The rats were housed in collective cages, with food and water ad libitum and were allowed an adaptation period of ten days before any procedure. For the purpose of this study the animals were divided in three groups.

* Control group (C) consisting of 17 non-operated rats, eight of which were studied in the third postoperative day (EarlyC) and nine in the $14^{\text {th }}$ postoperative day (LateC).

* Sham group (S), consisting of 17 animals undergoing sham HI procedure. Eight rats were studied in the third (EarlyS) and nine in the $14^{\text {th }}$ day (LateS) post sham HI procedure.

* Hypoxic-ischemic group (HI) consisting of 18 animals undergoing surgical ligature of the left carotid artery and exposure to hypoxic environment for three hours. Nine rats were studied in the third pos HI procedure day (EarlyHI) and nine in the $14^{\text {th }}$ post HI procedure day (LateHI).

\section{Experimental procedures}

After a 12-h fast, receiving only water ad libitum, the animals were weighed and randomly divided in the three experimental groups.

The animals allocated to the control group did not undergo any procedure and were returned to their cages.

\section{Hipoxic-ischemic (HI) procedure}

A total of 25 animals were allocated to the HI group. They were anesthetized by IP injection of $75 \mathrm{mg} / \mathrm{kg}$ of sodium pentobarbital, shaved and prepped. In these animals, a left cervicotomy was performed, through which the left carotid artery was identified and triple ligated with 3.0 silk. After a three hour recovery period the animals were put on a restrict environment, breathing a nitrogen balanced mixture containing only $8 \%$ oxygen, for three hours. Four animals died during the hypoxic period and three had to be euthanized because of seizures, leaving 18 animals for evaluation.

\section{Sham procedure}

The animals from the SHAM group were anesthetized and underwent sham cervicotomy without manipulation of the carotid artery. After recovery they were put in the same type of cages as the animals from the HI group, but were allowed to breathe room air instead.

\section{Evaluation of gastric emptying}

GE was estimated indirectly by measuring percent gastric retention (\%GR) of a saline test meal according to the method of Collares et $a l .{ }^{12}$ as following. Every procedure was undertaken after a 22-hour fast. Water ingestion was stopped at the beginning of the procedure. Test meal was infused by gravity, through a metallic orogastric catheter with a multiperforated olive in its distal end. Passage of the olive into the stomach was confirmed by a drop in the resistance to the progression of the catheter. Test meal consisted of $2 \mathrm{ml} / 100 \mathrm{~g}$ of rat weight of saline solution containing $6 \mathrm{mg} / 100 \mathrm{ml}$ of phenol red as a marker. After the infusion, the catheter was removed and the animal returned to its cage for exactly 8.5 minutes. At this moment, the animal was placed in a glass container with ethylic ether for a 60 -second period. Once the animal was anesthetized, the orogastric catheter was reintroduced, the abdomen was opened and the pylorus clamped exactly 10 minutes after the end of the orogastric infusion. Gastric contents were aspirated and the stomach washed four times with $2 \mathrm{ml}$ of distilled water. Total emptying of the stomach was confirmed by direct visualization. This volume (gastric contents plus washing volume) was placed in a graduated bottle. The gastric catheter and the syringe used in the procedure were also washed with $8 \mathrm{ml}$ of distilled water, and this volume was placed in that same bottle and the total volume annotated (volume B). Half milliliter of test meal (volume A) or $2 \mathrm{ml}$ of volume B were placed, in duplicate, in 10-ml bottles that were previously filled with $5 \mathrm{ml}$ of $27.5 \mathrm{mg} / \mathrm{ml}$ trissodic phosphate and distilled water to achieve a final volume of $10 \mathrm{ml}$. Readings were done in a spectrophotometer with wave length of $560 \mathrm{~nm}$. Percent gastric retention at 10 minutes $\left(\mathrm{GR}_{10}\right)$ was calculated using the following formula:

$$
\mathrm{GR}_{10}=(\mathrm{B} * \mathrm{~b} * 100) /(\mathrm{A} * \mathrm{a} * 4)
$$

where: $\mathrm{A}=$ volume of the test meal; $\mathrm{B}=$ total recovered volume; $\mathrm{a}=$ spectrophotometer reading of test meal; $\mathrm{b}=$ spectrophotometer reading of gastric contents.

\section{Evaluation of the brain injury}

Brain injury was initially evaluated clinically by the presence of ptosis of the left eyelid and/or a slight sideway gait. After cerebral perfusion with formalin, the animals from the sham and HI groups had their brains excised, weighed in a high precision scale and sent for histological analysis, to look for signs of brain injury. The values were expressed as grams of brain / $100 \mathrm{~g}$ of body weight in order to correct for differences among the animals.

\section{Statistical analysis}

The means of brain weight were compared by Student's t test. Mean gastric retentions were compared among the three study groups using ANOVA. A value of $\alpha=0.05$ was used as statistical significant.

\section{Results}

\section{Brain injury}

All surviving animals from the HI group displayed ptosis of the left eyelid and 6 of them developed a mild sideway gait. Mean corrected brain weigh values are represented in Table 1 and Figure 1. 
TABLE 1 - Mean and SEM of brain weight (g/ 100g body weight) of the animals of the sham and HI groups, evaluated in the Early ( $3^{\text {rd }}$ day) and Late $\left(14^{\text {th }}\right.$ day) post HI period

\begin{tabular}{l|cc|cc}
\hline & \multicolumn{2}{|c|}{ EARLY } & \multicolumn{2}{c}{ LATE } \\
& Mean & SEM & Mean & SEM \\
\hline Sham & 1.26 & 0.17 & 1.06 & 0.11 \\
HI & 1.42 & 0.28 & 0.97 & 0.05 \\
\hline
\end{tabular}
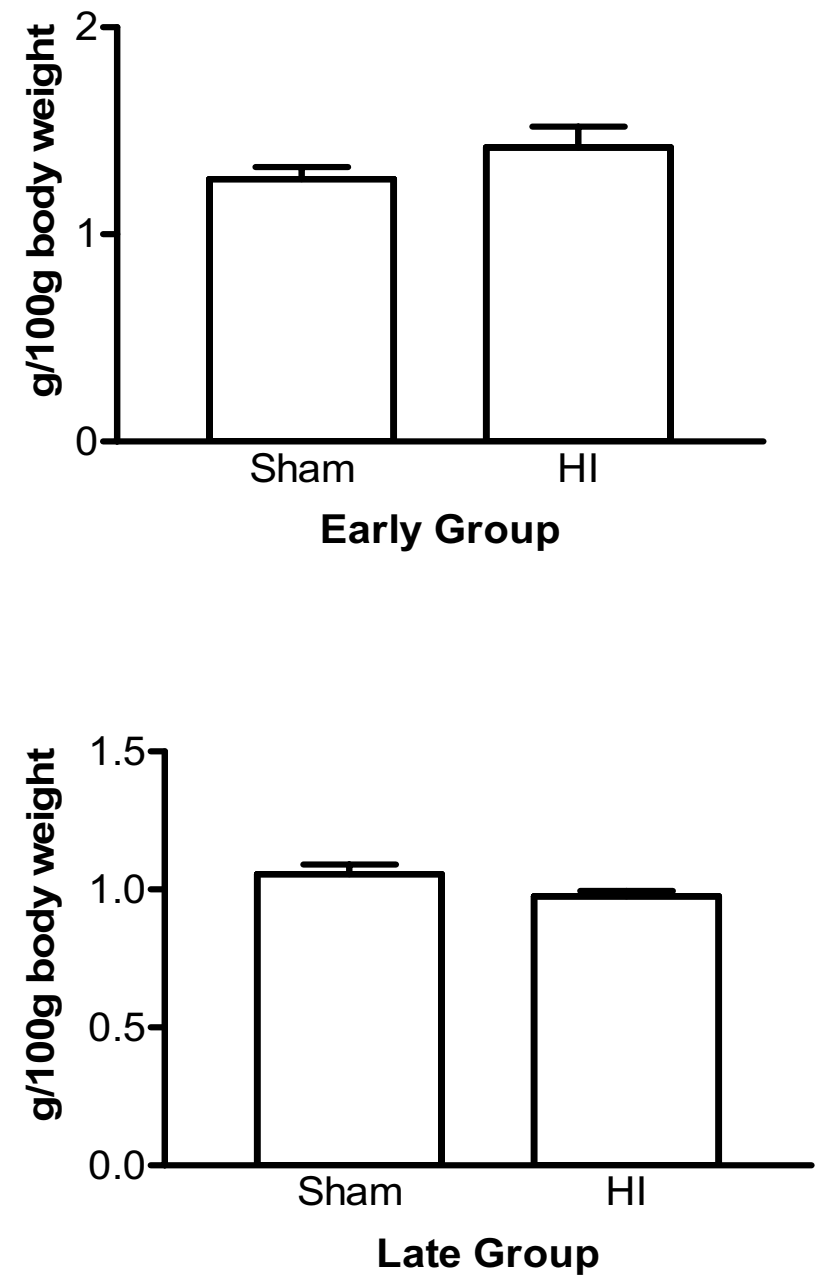

FIGURE 1 - Graphic representation of the mean \pm SEM of the cerebral weight values observed in the experimental groups, both in the Early ( $3^{\text {rd }}$ day) and Late (14 ${ }^{\text {th }}$ day) evaluations. There was no statistical difference between the groups

It can be seen that in the Early period, although without statistical significance, there was a tendency to an increase in the mean brain weight of the hypoxic animals suggesting a slight degree of brain swelling. On the contrary, on the $14^{\text {th }}$ postoperative day, the corrected mean brain weight of the animals of the HI group was marginally lower $(p=0.0591)$ than that of the animals from the sham group, a feature that might indicate impending atrophy. Histological analysis of the brains from the HI group revealed a diffuse neuronal injury involving the cortex, hippocampus and basal nucleus. The neurons look elongated, rhomboid, and had reduced cytoplasmatic and nuclear volumes.
Confirming the clinical observations, sections of the brain of the animals from the Early group displayed increased celularity (modified neurons, oligodendrocites, glias) together with small areas of infarction while the sections of the brain of the animals from the Late group showed decreased celularity, with distorted neurons, suggestive of regenerating areas.

\section{Gastric emptying}

The mean values of $\%$ GR are summarized in Table 2 and Figure 2.

TABLE 2 - Mean and SEM of gastric retention values $\left(\% \mathrm{GR}_{10}\right)$ observed on the animals of the three study groups, evaluated in the Early ( $3^{\text {rd }}$ day) and Late (14 $4^{\text {th }}$ day) post HI period

\begin{tabular}{l|cc|cc}
\hline & \multicolumn{2}{|c|}{ EARLY } & \multicolumn{2}{c}{ LATE } \\
& Mean & SEM & Mean & SEM \\
\hline Control & 32.58 & 3.18 & 30.42 & 1.89 \\
Sham & 30.09 & 1.51 & 27.76 & 0.92 \\
HI & 32.16 & 2.36 & 30.70 & 1.76 \\
\hline
\end{tabular}
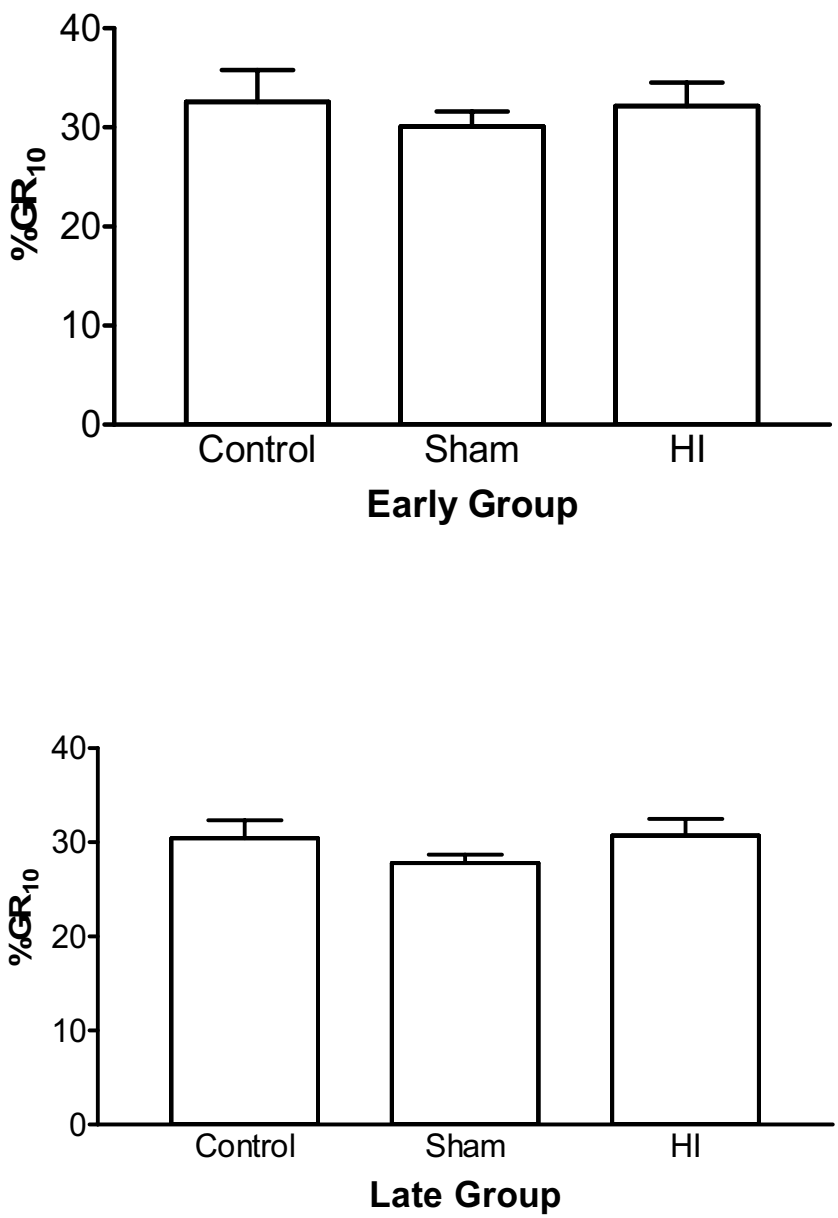

FIGURE 2 - Graphic representation of the mean \pm SEM of the percent gastric retention $\left(\% \mathrm{GR}_{10}\right)$ observed in the experimental groups, both in the Early ( $3^{\text {rd }}$ day) and Late $\left(14^{\text {th }}\right.$ day) evaluations. There was no statistical difference between the groups. Statistical analysis of the data revealed no statistical difference among the mean values of \%GR in the three study groups, both in the early and in the late evaluations 


\section{Discussion}

It is well known that, among neurologically impaired children, GERD is not only very common but also exhibits a very poor response both to clinical measures and surgical treatment, suggesting that some unrecognized mechanisms may be involved in its pathogenesis ${ }^{1,5,7}$. Abdominal spasticity, permanence in the recumbent position for long periods of time, poor function of the diaphragmatic crura are only a few of the factors incriminated in the genesis of reflux in this group of children.

The presence of a diffuse gastrointestinal motility syndrome has gained acceptance as a possible cause of GERD. Because delayed gastric emptying is a common finding among NI children with GERD, it has been held responsible not only for the development of reflux but also for the high rate of postoperative recurrence $e^{7,13-15}$. However, due to the highly symptomatic complexity of these patients and to the existence of ethical limitations, the causes of this delayed gastric emptying are not yet completely understood.

In this initial experiment we sought to investigate the effect of isolated hypoxic ischemic brain injury over gastric motility. This type of injury has been selected because most of the NI children referred for antireflux surgery have either experienced perinatal hypoxic problems or have been victims of near-drowning ${ }^{2}$. Also, this is a well established experimental model that has been widely employed to study many different aspects of neurological diseases ${ }^{11-16}$.

In the present experiment, both the clinical observations and the anatomical findings on the animals' brains confirmed the presence of brain injury, which, because of the way it was produced, was thought to be comparable to the one present in those NI children referred for antireflux operation.

Under these experimental conditions, however, the results showed that the sole presence of ischemic brain injury was not associated with delayed gastric emptying of a $0.9 \%$ saline meal.

A few hypotheses may be raised to explain these findings. First, although we could not substantiate it, it is possible that the experimental model may have produced a weaker brain injury than that observed in NI children. For instance, it is a fact that most of these children have often uncontrolled seizures. However, according to directions of the bioethical committee, the development of seizures in the experimental animals was considered as unnecessary suffering and accordingly, those animals had to be euthanized and excluded from the experiment. While this may have produced a bias towards a milder form of injury, on the other hand it also indicates a possible role of seizures and resulting increased intraabdominal pressure as causes of the delay in gastric emptying.

Nonetheless it is believed that the effect of a more profound (or more chronic) neurological lesion should be investigated.

Another frequently underestimated problem is the use, by these children, of various neurotropic medications, especially those employed to control seizures and restlessness. Many of those drugs are associated with diffuse poor intestinal motility ${ }^{17,18}$. Also, the fact that they are taken chronically, makes it possible that even their eventual suspension one or two days before GE studies does not completely erase their effect on motility. Based on these results, it could be questioned if the motility alterations reported in NI children, such as constipation and delayed gastric emptying, might, at least partially, represent a secondary effect of those medications, instead of being a direct consequence of the brain injury.

Further studies, using different mechanisms of brain injury, are deemed necessary to increase our understanding of the physiopathology of GERD in children with profound neurological disabilities.

\section{Conclusion}

Mild to moderate neurological impairment was not associated with a delay in the gastric emptying of liquids.

\section{References}

1. Del Buono R, Wenzl TG, Rawat D, Thomson M. Acid and nonacid gastro-oesophageal reflux in neurologically impaired children: investigation with the multiple intraluminal impedance procedure. J Pediatr Gastroenterol Nutr. 2006;43:331-5.

2. Lasser MS, Liao JG, Burd RS. National trends in the use of antireflux procedures for children. Pediatrics. 2006;118:1828-35.

3. Tovar JA, Luis AL, Encinas JL, Burgos L, Pederiva F, Martinez L, Olivares P. Pediatric surgeons and gastroesophageal reflux. J Pediatr Surg. 2007; 42:277-83.

4. Sullivan PB. Gastrointestinal problems in the neurologically impaired child. Baillieres Clin Gastroenterol. 1997;11:529-46.

5. Ravelli AM, Milla PJ. Vomiting and gastroesophageal motor activity in children with disorders of the central nervous system. J Pediatr Gastroenterol Nutr. 1998;26:56-63.

6. Bustorff-Silva J. Electrogastrography for evaluating neurologically impaired children with recurrent vomiting. J Pediatr Gastroenterol Nutr. 1998;27:373-4.

7. Bustorff-Silva J, Fonkalsrud EW, Perez CA, Quintero R, Martin L, Villasenor E, Atkinson JB. Gastric emptying procedures decrease the risk of postoperative recurrent reflux in children with delayed gastric emptying. J Pediatr Surg. 1999;34:79-82.

8. Dedinsky GK, Vane DW, Black T, Turner MK, West KW, Grosfeld JL. Complications and reoperation after Nissen fundoplication in childhood. Am J Surg. 1987;153:177-83.

9. Pearl RH, Robie DK, Ein SH, Shandling B, Wesson DE, Superina R, Mctaggart K, Garcia VF, O'Connor JA, Filler RM. Complications of gastroesophageal antireflux surgery in neurologically impaired versus neurologically normal children. J Pediatr Surg. 1990;25:1169-73.

10. Spitz L, Roth K, Kiely EM, Brereton RJ, Drake DP, Milla PJ. Operation for gastro-oesophageal reflux associated with severe mental retardation. Arch Dis Child. 1993;68:347-51.

11. Rice JE, Vannucci RC, Brierley JB. The influence of immaturity on hypoxic-ischemic brain damage in the rat. Ann Neurol. 1981;9:131-41.

12. Collares EF, Vinagre AM. Effect of the GABAB agonist baclofen on dipyrone-induced delayed gastric emptying in rats. Braz J Med Biol Res. 2005;38(1):99-104.

13. Alexander F, Wyllie R, Jirousek K, Secic M, Porvasnik S. Delayed gastric emptying affects outcome of Nissen fundoplication in neurologically impaired children. Surgery. 1997;122:690-7.

14. Bustorff-Silva J, Perez CA, Fonkalsrud EW, Hoh C, Raybould HE. Gastric emptying after fundoplication is dependent on changes in gastric volume and compliance. J Pediatr Surg. 1999;34:1232-5.

15. Maxson RT, Harp S, Jackson RJ, Smith SD, Wagner CW. Delayed gastric emptying in neurologically impaired children with gastroesophageal reflux: the role of pyloroplasty. J Pediatr Surg. 1994;29:726-9.

16. Vannucci RC, Connor JR, Mauger DT, Palmer C, Smith MB, Towfighi J, Vannucci SJ. Rat model of perinatal hypoxic-ischemic brain damage. J Neurosci Res. 1999;55:158-63. 
17. Koch KL. Diabetic gastropathy: gastric neuromuscular dysfunction in diabetes mellitus. A review of symptoms, pathophysiology and treatment. Dig Dis Sci. 1999;44:1061-75.
18. Lin HC, Hasle WL. Disorders of gastric emptying. In: Yamada T. (ed). Textbook of gastroenterology. Philadelphia: JB Lippincott; 1995. p.1318-46.

Conflict of interest: none

Financial source: none

\section{Correspondence:}

Joaquim Bustorff-Silva

Division of Pediatric Surgery

State University of Campinas

Rua Alexander Fleming, 181

Cidade Universitária "Zeferino Vaz"

13083-970 Campinas - SP Brazil

Phone/Fax: (55 19)3521-7033

bustorff@hc.unicamp.br

Received: May 20, 2008

Review: July 15, 2008

Accepted: August 14, 2008

\section{How to cite this article}

Melro APC, Collares EF, Bustorff-Silva JM. Effect of an isolated mild to moderate ischemic brain injury in the gastric emptying of liquids in rats. Acta Cir Bras. [serial on the Internet] 2008 Nov-Dec;23(6). Available from URL: http://www.scielo.br/acb 